\title{
MUDANÇA TERAPÊUTICA E MOMENTOS DE INOVAÇÃO
}

\author{
Miguel M. Gonçalves ${ }^{1}$ \\ Anita Santos $^{2}$ \\ Marlene Matos $^{3}$ \\ Inês Mendes ${ }^{4}$ \\ Carla Martins 5
}

Resumo: De acordo com White e Epston (1990), a construção da mudança em psicoterapia ocorre a partir da ampliação de resultados únicos, ou de momentos de inovação (MIs), como preferimos denominá-los. Os resultados únicos são excepções à história saturada pelo problema que podem viabilizar uma nova narrativa. Neste estudo, analisam-se os MIs em cinco casos com bons resultados terapêuticos e cinco casos com reduzido sucesso terapêutico. Os resultados revelam que há diferenças significativas ao nível da saliência (tempo de elaboração na sessão), que é mais elevada no grupo com bons resultados terapêuticos, e em relação aos MIs de reconceptualização e novas experiências, tipos de MIs que estão quase ausentes no grupo com insucesso. Sugere-se um modelo de construção de novas narrativas em que os MIs de reconceptualização possibilitam o desenvolvimento de uma meta-posição sobre o próprio processo de mudança. Deste modo, promove-se o desenvolvimento do sentido de autoria da narrativa de vida e também de novos guiões para a mesma (MIs de novas experiências).

Palavras-chave: Mudança narrativa, momentos de inovação, reconceptualização, novas experiências.

Therapeutic change and innovative moments (Abstract): According to White and Epston (1990), psychotherapeutic change occurs through the elaboration of unique outcomes, or Innovative Moments (IMs), as we prefer to call them. Unique

\footnotetext{
${ }^{1}$ Universidade do Minho, e-mail: mgoncalves@iep.uminho.pt

2 ISMAI, Instituto Superior da Maia, e-mail: anitasantos@docentes.ismai.pt

${ }^{3}$ Universidade do Minho, e-mail: mmatos@iep.uminho.pt

${ }^{4}$ Universidade do Minho, e-mail: inesmendes88@gmail.com

${ }^{5}$ Universidade do Minho, e-mail: cmartins@iep.uminho.pt

A correspondência sobre este artigo deve ser dirigida a Miguel M. Gonçalves, Departamento de Psicologia, Universidade do Minho, 4710 Braga, Portugal.

Apoios: Este artigo foi apoiado pela Fundação para a Ciência e a Tecnologia (FCT) com a bolsa PTDC/PSI/72846/2006 (Narrative Processes in Psychotherapy).
} 
outcomes are exceptions to the problem saturated story that allow a new narrative to emerge. In this study, IMs are analyzed in five cases with good therapeutic outcomes and five cases with poor outcomes. Results show differences regarding the salience index (time devoted to the IMs in the session), which is higher in the good outcomes group. Data also reveal that reconceptualization and new experiences of IMs are almost absent in poor outcomes cases. We suggest a model of construction of new narratives, where reconceptualization of IMs allows the development of a meta-position over the change process. Thus, clients become authors of their own self narratives and develop new life scripts (new experiences of IMs).

Key-words: narrative change, innovative moments, reconceptualization and new experiences.

\section{Resultados únicos e mudança}

A terapia narrativa de re-autoria, iniciada por White e Epston (1990), deu origem a várias formas de intervenção terapêutica, tendo-se tornado num dos mais influentes modelos de terapia narrativa (ver Freedman \& Combs, 1996; Monk, Winslade, Crocket, \& Epston, 1997; Parry \& Doan, 1994; Smith \& Nylund, 1996; Winslade \& Monk, 1999; White, 2004, 2007; Zimmerman \& Dickerson, 1996). Na perspectiva deste modelo, bem como de outras terapias discursivas (e.g., Angus \& McLeod, 2004, Hoyt, 1998; Neimeyer \& Raskin, 2000; Omer \& Alon, 1997), os clientes mudam as suas narrativas de vida, não porque a terapia permita corrigir processos psicológicos disfuncionais, mas porque possibilita a construção de novas narrativas de vida, mais adaptativas.

Assim, de acordo com o modelo narrativo de re-autoria (White \& Epston, 1990), a construção de narrativas de vida novas e preferenciais resultam da identificação e da elaboração de resultados únicos. A definição de resultado único (RU) consiste na emergência na terapia de um detalhe narrativo (e.g., episódio) que não é congruente com a narrativa saturada pelo problema (e.g., depressão, ansiedade). White (2007) refere-se inúmeras vezes ao conceito de narrativa saturada pelo problema (ou narrativa totalitária) dado que, na larga maioria de situações de sofrimento, as pessoas têm de algum modo as suas vidas reduzidas a um tema totalizador, que impede ou dificulta a emergência de novidade e de diversidade, isto é de resultados únicos. Weakland caracteriza bem esta ideia ao dizer: "Life is one dawn thing after another (...) But people who seek therapy are no longer experiencing that - life for them has become the same damn thing over and over 
and over» (cit. por O'Hanlon, 1998, pp. 143-144). Um RU pode assumir uma grande diversidade de formas (e.g., um pensamento, uma recordação, uma acção, um projecto) mas é sempre algo que se situa, de algum modo, fora da influência da narrativa saturada pelo problema ou, nas palavras de Weakland, fora do âmbito da «same damn thing over and over and over».

Apesar do grau de persistência dos problemas, todos os clientes vivenciam RUs. Habitualmente os RUs não conduzem espontaneamente à emergência de uma nova história porque são desvalorizados ou ignorados. A narrativa problemática é dominante e não permite que o indivíduo contemple novas formas de agir, sentir e pensar. Os RUs, em termos terapêuticos, são considerados oportunidades para a construção de novas histórias e constituem-se, assim, como oportunidades para que a mudança terapêutica ocorra.

White e Epston (1990; White, 2007) recorrem à distinção proposta por Bruner (1986) entre paisagem de acção e paisagem de consciência que caracteriza o modo narrativo de pensamento. Para Bruner (1986), as boas histórias são escritas nestas duas paisagens. A paisagem da acção descreve o setting, as personagens envolvidas e as suas acções, enquanto a paisagem da consciência descreve os sentimentos, os valores, as crenças e os projectos das personagens, que conferem um sentido mais coerente à narrativa. Deste modo, na sequência da proposta de White e Epston (1990), Freedman e Combs (1996) sugerem que, após a desconstrução de narrativas problemáticas, o terapeuta deve enfatizar a conversação em torno dos RUs na paisagem da acção (e.g., o terapeuta coloca questões do tipo "como é que esta novidade ocorreu?" ou "o que aconteceu, em que sequência, envolvendo que personagens?" (p. 318, Freedman e Combs, 2002) e relacioná-los com RUs na paisagem da consciência (e.g., "Que características suas se evidenciaram nesta situação? Quais os valores que se tornaram visíveis face a este novo acontecimento?"). Quando o terapeuta e o cliente conversam acerca dos significados envolvidos nestas sequências de RUs que foram elaborados na paisagem da acção, passam a construir a história na paisagem da consciência. Nesta construção, a elaboração de RUs envolve expectativas, desejos, valores ou crenças. Freedman e Combs (1996) propõem uma estrutura terapêutica em que a consolidação de uma nova história se faz através do questionamento em torno dos RUs. As questões oscilam entre elementos da paisagem da acção e elementos da paisagem da consciência, partindo de um determinado tempo (e.g., presente) e articulando-o com outros tempos (e.g., passado), incrementando assim a plausibilidade narrativa (e.g., para uma descrição técnica deste processo cf. Freeman \& Combs, 1996; White, 2007). De acordo com os autores, este processo leva à transformação dos RUs em novas histórias e novos significados sobre si. Metaforicamente, estas três dimensões - tempo, acção e consciência - actuam como vectores na matriz narrativa, uma vez que promovem a emergência de uma nova 
história. Assim, na conversação terapêutica, terapeutas e clientes necessitam de desenvolver estas três dimensões, de modo a que a nova história adquira consistência e se torne uma alternativa viável à história saturada pelo problema. A dimensão temporal é fundamental para permitir o desenvolvimento coerente dos acontecimentos, sem a qual a história se tornaria caótica. Mas apenas a dimensão temporal não é suficiente para que uma boa história se desenvolva - também são necessárias acções e emoções, valores e pensamentos, assim como outros elementos das paisagens da acção e da consciência. Estes elementos são centrais para que uma história seja significativa e plausível para a pessoa que a está a construir (e a viver, à medida que a construção vai prosseguindo).

De modo análogo, de Shazer $(1991,1994)$ sugere que o terapeuta deve evitar uma conversação centrada no problema e deve ser capaz de transformar a forma tradicional de entrevistar clientes numa forma que se centre nas excepções. De Shazer (1991) adverte para o facto de não confundir um diálogo em torno das excepções com a conversação sobre as excepções com o problema em plano de fundo. Assim, em vez de falar sobre a ausência do problema, o terapeuta procura entrevistar o cliente sobre a presença de algo que se torna possível porque o problema está ausente (cf. Gonçalves, 2008). É, pois, a presença de algo diferente do problema (e também diferente da sua ausência) que permite a construção de novidade e a "dissolução" das histórias problemáticas.

A principal diferença entre White e Epston (1990) e De Shazer (1991) é que, do ponto de vista de De Shazer, as excepções não requerem uma "textura" narrativa para que a mudança ocorra. Deste modo, o terapeuta centrado nas soluções não enfatiza a construção de uma nova história segundo a matriz narrativa referida anteriormente. O terapeuta preocupa-se com a criação de uma narrativa progressiva em torno do contexto terapêutico, ou seja, o cliente deverá sentir que a terapia o levará a algum lado e que está a fazer progressos. Por outro lado, White $(1994,2007)$ considera os RUs como sendo mais do que excepções aos problemas, uma vez que estes são compreendidos como excepções à narrativa problemática.

Apesar das suas diferenças, quando comparados com abordagens mais tradicionais (e.g., psicodinâmica, cognitiva), estes dois modelos de terapia partilham uma característica principal: em vez de tentar resolver problemas ou corrigir disfunções, eles tentam construir a mudança através das excepções em si mesmas, quer sejam narrativamente estruturadas, ou não. Por outras palavras, a mudança terapêutica ocorre pela elaboração narrativa de novidades e não pela modificação de padrões disfuncionais.

Do nosso ponto de vista, a terapia narrativa é útil na intervenção com mulheres vítimas de violência na intimidade (população alvo deste estudo) por diversas razões (cf. Matos \& Gonçalves, 2004). Em primeiro lugar, a 
violência conjugal é uma experiência que produz diversos efeitos prejudiciais que moldam a narrativa de si própria, usualmente dominada pela auto-culpabilização, vergonha, confusão, cepticismo e hesitação perante a possibilidade de mudança (Martin, Berenson, Griffing, Sage, Madry, Bingham \& Primm, 2000; Matos, 2006). Em segundo lugar, estas dificuldades são alimentadas pela fusão entre o problema e o self (e.g., "a culpa dos maus-tratos é minha", "se eu fosse melhor esposa ele não me batia"). As práticas de exteriorização do problema, propostas pela terapia narrativa, permitem precisamente criar a distinção entre o que o problema "quer" para a vida da cliente e o que a pessoa prefere, criando um novo espaço de desenvolvimento da agência pessoal. Em terceiro lugar, a proposta narrativa centra-se na desconstrução de discursos sociais e culturais, sendo a violência na intimidade um domínio em que os discursos sociais (e.g., de género, da família tradicional) suportam claramente a violência do parceiro e frequentemente dificultam a mudança pessoal (Madigan \& Law, 1998). Tornar estas práticas e valores sociais explícitos permite que as clientes se reposicionem face a estes discursos dominantes, descobrindo neste movimento novas práticas e valores (e.g., tolerância, igualdade).

Baseados na terapia narrativa e numa anterior investigação (Matos \& Gonçalves, 2004), construímos um sistema de codificação de RUs - o Sistema de Codificação dos Momentos de Inovação - que nos permite identificar diferentes tipos de RUs. Foram discutidas previamente (Gonçalves, Matos \& Santos, 2009) as razões pelas quais preferimos a designação de momentos de inovação (MIs) em vez de RUs. Em primeiro lugar, não parece existir algo de "único" nos RUs, pois, tal como a teoria sugere e a prática reitera, eles ocorrem frequentemente na psicoterapia (ver de Shazer, 1991, para uma crítica semelhante). Em segundo lugar, a noção de "resultado" é algo contraditória com o que a literatura sugere, pois estas ocorrências são parte do processo de construção de uma nova narrativa. Assim, preferimos a designação MIs.

Numa investigação anterior (Matos, 2006), identificámos cinco tipos de MIs: (1) acção, (2) reflexão, (3) protesto, (4) reconceptualização e (5) novas experiências.

(1) MIs de Acção envolvem acções específicas face ao problema e às suas consequências; (2) MIs de Reflexão implicam a emergência de novas compreensões ou de pensamentos diferentes face à narrativa dominante; (3) MIs de Protesto podem envolver acções ou pensamentos (como os MIs anteriores), mas requerem mais do que meras acções ou pensamentos, uma vez que envolvem uma forma de reposicionamento de si próprio e, dessa forma, emerge um processo de maior pró-actividade através de um protesto face à história saturada pelo problema e suas especificações (e.g., tomar uma decisão que reduz o poder da história problemática); (4) MIs de Reconceptuali- 
zação são mais complexos, implicando uma compreensão a um nível metacognitivo, em que o cliente percebe algo de diferente em si próprio em relação ao passado, mas também é capaz de descrever quais os processos envolvidos na transformação. Envolvem a distinção entre uma posição anterior e uma presente, bem como os processos que deram origem a essa transformação; (5) MIs de Novas Experiências referem-se ao planeamento ou experiência de novos projectos, actividades, ou relacionamentos interpessoais, que estavam impedidos pelos constrangimentos da narrativa problemática.

Quadro 1. Tipologia e Exemplos de MIS

\begin{tabular}{|c|c|}
\hline Tipos de MI & Exemplos \\
\hline $\begin{array}{l}\text { MI Acção (A) } \\
\text { Acções ou comportamentos } \\
\text { específicos de desafio ao pro- } \\
\text { blema. }\end{array}$ & $\begin{array}{l}\text { Novos desempenhos face à antecipada ou } \\
\text { efectiva reinstalação de um obstáculo. } \\
\text { Resolução efectiva de problemas } \\
\text { Exploração activa de soluções específicas } \\
\text { Restabelecimento de autonomia e auto- } \\
\text {-controlo. } \\
\text { Procura de informação sobre o problema }\end{array}$ \\
\hline $\begin{array}{l}\text { MI Reflexivos (R): } \\
\text { Excepções de carácter cogniti- } \\
\text { vo ou produtos cognitivos (ex. } \\
\text { pensamentos, intenções, inter- } \\
\text { rogações, dúvidas) que indi- } \\
\text { ciam a compreensão de algo } \\
\text { novo e que não legitimam o } \\
\text { problema. }\end{array}$ & $\begin{array}{l}\text { Compreensão - o cliente compreende as cau- } \\
\text { sas do problema, percebe a sua etiologia, } \\
\text { suas consequências e efeitos } \\
\text { Nova formulação do problema } \\
\text { Intenção de combater o problema, auto- } \\
\text {-instruções funcionais ou pensamentos } \\
\text { adaptativos } \\
\text { Articulação de dilemas cognitivos e afectivos } \\
\text { Processo terapêutico - reflexão sobre o pro- } \\
\text { cesso terapêutico } \\
\text { Processo de mudança - o cliente elabora } \\
\text { sobre qual o processo e estratégias imple- } \\
\text { mentados para dominar o problema } \\
\text { Novas posições - emergência de novas posi- } \\
\text { ções face às prescrições do problema } \\
\text { Sentimentos de bem-estar, auto-valorização }\end{array}$ \\
\hline
\end{tabular}

\section{Protesto (P)}

Momentos de dissidência atitudinal, envolvendo de algum modo confronto (endereçado a outrem ou a facetas de si próprio). Podem envolver comportamentos, pensamentos e sentimentos, projectados ou concretizados.
Posição de crítica/confronto face ao problema e a outros (pessoas, sociedade, ...) que o suportam/mantêm

Posições assertivas face aos outros e empowerment 


\begin{tabular}{|c|c|}
\hline $\begin{array}{l}\text { MI Reconceptualização (RC) } \\
\text { Descrição processual, a nível } \\
\text { metacognitivo (i.e., não só } \\
\text { surgem pensamentos e/ou } \\
\text { desempenhos fora da lógica do } \\
\text { problema, como emerge tam- } \\
\text { bém o processo subjacente). }\end{array}$ & $\begin{array}{l}\text { Redefinição das versões de si } \\
\text { Releitura da sua relação com os outros } \\
\text { Atribuição de novos significados (reenqua- } \\
\quad \text { dramento) a problemas prévios } \\
\text { Redefinição da versão elaborada acerca dos } \\
\text { outros }\end{array}$ \\
\hline $\begin{array}{l}\text { MI Novas Experiências (NE) } \\
\text { Referências a novas pretensões, } \\
\text { experiências/actividades ou } \\
\text { projectos em curso ou anteci- } \\
\text { pados. }\end{array}$ & $\begin{array}{l}\text { Generalização de ganhos para outras dimen- } \\
\text { sões da vida projectada no futuro } \\
\text { Reutilização da experiência problemática para } \\
\text { novas situações } \\
\text { Reinvestimentos em novos projectos resultan- } \\
\text { tes do processo de mudança } \\
\text { Reinvestimentos relacionais resultantes do } \\
\text { processo de mudança }\end{array}$ \\
\hline
\end{tabular}

\section{Estudo empírico}

Nesta investigação explora-se o modo como os MIs contribuem para o desenvolvimento de narrativas preferenciais na psicoterapia. Trata-se de um primeiro estudo de um projecto de investigação mais amplo, cujo objectivo é analisar o papel dos MIs na mudança psicoterapêutica.

Neste artigo procuramos perceber (1) se, tal como prediz a teoria, os MIs são importantes para o sucesso psicoterapêutico, ou seja, se emergem mais MIs em casos com bons resultados terapêuticos do que em casos com reduzido sucesso psicoterapêutico, (2) se diferentes tipos de MIs (e.g., acção, reflexão) emergem de forma diferente nos casos com sucesso e de insucesso psicoterapêutico, e (3) se diferentes MIs aparecem de um modo mais predominante em diferentes fases do processo terapêutico (e.g., início, fim da terapia).

\section{Método}

\section{Participantes}

Nesta investigação participaram mulheres vítimas de abuso por parte do parceiro, que foram alvo de psicoterapia individual, de orientação narrativa (White \& Epston, 1990). 


\section{Clientes}

As clientes foram atendidas no serviço de consulta de uma universidade portuguesa, tendo assinado uma declaração de consentimento informado, na qual constavam os objectivos da investigação. O acompanhamento terapêutico foi realizado gratuitamente.

A amostra é constituída por dez mulheres, com idades compreendidas entre os 22 e os 57 anos. Quatro destas mulheres não tinham filhos e as restantes tinham entre um a quatro filhos. No que respeita à sua qualificação académica, verificou-se uma grande variabilidade entre elas, desde o nível básico de ensino até ao ensino pós-graduado. Relativamente às profissões exercidas pelas participantes registou-se também uma grande variabilidade, desde profissões qualificadas até outras indiferenciadas. As relações abusivas tinham uma duração que variava entre um e vinte anos: quatro participantes foram alvo de vitimação prolongada (mais de cinco anos) e as restantes de uma vitimação mais breve (inferior a cinco anos). A violência psicológica estava presente em todos os casos. Simultaneamente, cinco mulheres eram vítimas de violência física e sexual.

Cinco mulheres foram conduzidas para a psicoterapia por outros psicólogos, duas foram enviadas pelo sistema judicial (polícia e tribunais), uma surgiu por iniciativa própria e duas foram encaminhadas por técnicos que apoiam vítimas de crime.

A maioria das clientes era casada, uma delas coabitava com o parceiro e duas namoravam (sem coabitação). No final da psicoterapia, quatro clientes terminaram a relação de intimidade.

Quatro parceiros foram acompanhados simultaneamente por outro psicoterapeuta. Dois deles terminaram o processo terapêutico com sucesso, outro desistiu e outro ainda permanecia na intervenção aquando do término deste estudo.

\section{Terapeuta}

Todos os casos foram atendidos pela mesma terapeuta (terceira autora) que possuía o grau de mestre em Psicologia no momento do estudo e cinco anos de experiência em psicoterapia com vítimas de violência conjugal. O modelo terapêutico foi desenvolvido a partir da terapia de re-autoria de White and Epston (1990, ver também White, 2007) envolvendo (1) a exteriorização do problema, que não o abuso (e.g., medo, tristeza, características pessoais que suportam o abuso), (2) a identificação das prescrições culturais e sociais que apoiam a violência sobre as mulheres (e.g., poder patriarcal, crítica acerca das mulheres que saem da relação), (4) o questionamento terapêutico acerca dos resultados únicos no sentido da criação de um novo guião, alternativo ao que foi anteriormente exteriorizado, e (5) a 
consolidação das mudanças alcançadas através da validação social (e.g., rituais de mudança, escrita de cartas dirigidas a mulheres com o mesmo problema). A supervisão foi realizada pelo primeiro autor e visou a monitorização da adesão da terapeuta ao modelo narrativo.

\section{Avaliação dos resultados terapêuticos}

De modo a avaliar os resultados terapêuticos, estabeleceu-se um protocolo de avaliação administrado em diferentes momentos ao longo da terapia: na primeira sessão, na quarta, na oitava, na décima segunda, na décima sexta, na última e na sessão de follow-up (após seis meses). Essa avaliação contemplou a sintomatologia clínica, a vitimação por parte do parceiro, a aliança terapêutica e as crenças associadas à violência conjugal. Os resultados deste protocolo foram particularmente importantes para constituir os grupos (sucesso e insucesso terapêutico), como será explicitado nos procedimentos. As medidas utilizadas foram:

Avaliação da sintomatologia clínica. O Inventário de Sintomas Psicopatológicos (Brief Symptom Inventory - B.S.I., L. Derogatis, 1982; versão portuguesa adaptada por C. Canavarro, 1999) foi utilizado na avaliação da sintomatologia clínica. O BSI é um instrumento de auto-relato, composto por 53 itens, organizado numa escala tipo Likert, (de 1, "nunca" a 5, "muitíssimas vezes"). A medida utilizada nesta investigação foi o Índice Geral de Sintomas (I.G.S.). Esta escala foi administrada a cada quatro sessões, com início na primeira sessão.

Vitimação recebida pelo parceiro. De forma a avaliar esta dimensão, procedeu-se a um registo clínico acerca da violência recebida pelo parceiro. As clientes eram questionadas, de quatro em quatro sessões, sobre comportamentos de abuso recebidos (físico, psicológico e/ou sexual), a sua frequência e gravidade, avaliados sob a forma de uma escala qualitativa (reduzido, médio, elevado).

Aliança Terapêutica. O Inventário da Aliança Terapêutica (Working Alliance Inventory - WAI, Horvath, 1982: versão portuguesa adaptada por Machado e Horvath, 1999) foi utilizado com o intuito de avaliar a qualidade da aliança terapêutica. Este instrumento é composto por três sub-escalas tarefa, objectivo e relação - cada uma com doze itens. As clientes respondiam através de uma escala de tipo Likert que variava entre um e sete, desde "nunca" a "muito frequentemente". Foram aplicadas duas versões do instrumento, uma para os clientes e outra para os observadores (dois observadores independentes cotaram o instrumento a partir da visualização das sessões). Esta escala foi administrada a cada quatro sessões, com início na primeira sessão. 
Crenças face à violência conjugal. A Escala de Crenças sobre Violência Conjugal (E.C.V.C., Matos, Machado \& Gonçalves, 2000) foi aplicada para avaliar as crenças das clientes face à violência. Esta escala é composta por 25 itens, que consistem em afirmações que se referem à legitimação da violência conjugal. As clientes respondiam de acordo uma escala de tipo Likert, desde 1 a 5 (de "totalmente em desacordo" a "totalmente de acordo"). A pontuação total foi utilizada em três momentos de avaliação (primeira sessão, última e follow-up). Esta escala evidencia uma elevada fidelidade (alpha de Cronbach de 0,90) e estudos anteriores demonstraram uma forte associação positiva entre actos de agressão por parte do parceiro e a pontuação global da escala (cf. Machado, Matos e Gonçalves, 2004).

\section{Avaliação do processo terapêutico}

Todas as sessões foram codificadas a partir do Sistema de Codificação dos Momentos de Inovação (Gonçalves, Matos \& Santos, 2006) Apresentamos de seguida ilustrações dos cinco diferentes tipos de MIs, tal como foram descritos previamente neste artigo.

(1) MI de Acção: Codifica-se quando a cliente descreve acções ou comportamentos específicos de desafio ao problema, tal como se ilustra de seguida (a negrito está assinalado o que foi codificado como MI).

Cliente: Entretanto em Agosto, não sei porquê, ele começa a tirar... à frente do miúdo, com 2 anos e tal... a tirar satisfações da minha vida de solteira. $\boldsymbol{E}$ eu a não lhe responder. $O$ meu filho ali... eu acho que estava a arrumar coisas no armário e ele dava-me estaladas e empurrões e mais coisas que eu não me lembro. "Porque é que fizeste aquilo? Tens que me explicar isso!". E eu continuei sem lhe responder. Eu só lhe dizia "leva-o (ao filho) daqui. Pega no teu filho e vai a qualquer sítio!" Eu não lhe respondia. Entretanto eu vou à cozinha, ele vem atrás de mim e bate-me na cara. Fiquei com um hematoma enorme no olho negro. Entretanto... talvez ele tenha visto o que fez...

Terapeuta: Pediu desculpa?

Cliente: Não. Ele nunca me pediu desculpa. Ele finalmente pegou no miúdo e saiu de casa. Eu saí também... sem saber muito bem o que havia de fazer... fui a uma bomba de gasolina e comprei uma máquina descartável e entretanto fui ao centro de saúde falar com uma médica. Ela registou o que aconteceu e tirou-me uma fotografia. Depois falámos sobre isso. 
(2) MI de Reflexão: Referem-se a excepções de carácter cognitivo ou produtos cognitivos (ex. pensamentos, intenções, interrogações, dúvidas) narrados pela cliente na sessão que indiciam a compreensão de algo novo e que não legitimam o problema.

Cliente: É engraçado, eu sempre fui realista em relação às outras pessoas, mas em relação às minhas situações eu acho que não sou tanto, exactamente porque sou muito altruísta... tenho uma tendência a pensar primeiro nos outros e depois em mim! O meu pai disse-me numa altura qualquer que eu era louca porque pensava primeiro nos outros e depois em mim, e tem a sua razão...

Terapeuta: Mas se está aqui...

Cliente: Não, de há uns tempos para cá comecei a pensar um bocado mais em mim!

(3) MI de Protesto: O protesto é codificado quando a cliente narra episódios de dissidência atitudinal, que envolvem, de algum modo, confronto (endereçado a outrem ou a facetas de si próprio). Podem compreender comportamentos, pensamentos e sentimentos, projectados ou concretizados.

Cliente: Por exemplo, na semana passada até se estava bem. Mas ele dizia "dá-me mais uma oportunidade" $\boldsymbol{e}$ eu disse "dei-te quatro anos delas, não tenho mais para te dar. Desculpa, não acredito nem confio em ti, e tiveste quatro anos para mudar."

(4) MI de Reconceptualização: Este MI é mais complexo do que os anteriores e codifica-se a partir da verificação de dois critérios: a cliente identifica o contraste entre posições identitárias anteriores e actuais, e também descreve o processo de mudança. Implica uma posição a um nível metacognitivo (i.e., não só surgem pensamentos e/ou desempenhos fora da lógica do problema, como emerge também o processo subjacente).

Terapeuta: Até que ponto é um recurso para si recordar o passado?

Cliente: Por exemplo, mesmo em relação a mim mesma, às atitudes que eu tomo no dia-a-dia, no relacionamento com as pessoas, eu começo... eu às vezes olho para trás e penso, vejo o que fiz agora e olho para trás e penso... engraçado há dois anos atrás eu era incapaz de fazer isto! Não tinha... parecia que tinha o cérebro parado, enquanto eu agora reajo, penso eu, adequadamente às coisas. Tenho tido situações esporádicas, de mal entendidos, que se fosse há uns tempos atrás ficava caladinha, quietinha no meu canto e não dizia nada. Agora não, agora levanto-me e falo, não deixo que me passem por cima, que era uma coisa que eu deixava que me fizessem.

(5) MI de Novas Experiências: Este MI surge quando são relatadas referências a novas pretensões, actividades ou projectos. Estes surgem em 
resultado da mudança alcançada e podem estar já em curso ou simplesmente antecipados.

Cliente: Eu estava há tanto tempo ansiosa por esta mudança, embora nunca pensasse que acontecesse como aconteceu... que há uma vontade tremenda de... há muitas coisas que eu gostava de conseguir, mesmo a nível pessoal, coisas que agora quero mudar, muitas coisas mesmo. Uma delas passa por... porque eu sou uma pessoa um bocado desorganizada... $e$ isso há muito tempo que fazia parte dos meus planos começar a tentar modificar, a organizar-me.

Terapeuta: Agora está numa posição para mudar isso...

Cliente: É uma das coisas que eu quero começar fazer!

\section{Procedimentos}

Após finalizados os processos terapêuticos, as sessões foram analisadas com o Sistema de Codificação dos Momentos de Inovação (Gonçalves, Matos \& Santos, 2006).

A codificação envolveu a visualização de cada sessão terapêutica em vídeo e consequente registo, momento a momento, da emergência dos MIs à medida que surgiam na sessão. Para cada tipo de MI foram registados o tipo (e.g., acção, reflexão) e a duração de cada um (i.e., saliência). As sessões foram codificadas de forma sequencial (sessão 1,2 ... até à ultima e follow-up).

Para cada sessão calculámos o índice da saliência de cada MI, em percentagem, a partir do tempo dedicado a cada um e do tempo total de cada sessão.

Posteriormente, e de acordo com a avaliação dos resultados terapêuticos, foram definidos os dois grupos contrastantes - um grupo com sucesso e um grupo com insucesso. Esta diferenciação foi efectuada a partir da verificação de dois critérios: considerou-se que a mudança terapêutica ocorreu quando se verificou 1) uma redução significativa nos sintomas clínicos tal como avaliados pelo B.S.I. e 2) a cessação ou uma mudança significativa na vitimação recebida pelo parceiro, do início para o final da terapia. Este último critério envolve uma alteração importante no padrão de vitimação, tal como passar para formas "menores" de violência (e.g., insultar, gritar), e também uma modificação na prevalência dos episódios - passar de uma frequência contínua para uma de natureza ocasional.

Assim, o grupo com sucesso era constituído por cinco participantes que evoluíram para uma condição de sintomatologia clínica não relevante, e, simultaneamente, a vitimação cessou (em três casos), ou sofreu uma mudança significativa (em dois casos). $\mathrm{O}$ grupo com insucesso integrou, igualmente, cinco clientes. Duas das mesmas mantiveram, no final da terapia, sofrimento psicológico, e as restantes não reportaram uma mudança 
significativa nos padrões e prevalência da violência. Neste grupo incluíram-se ainda três desistências (drop-outs).

Não se verificaram diferenças entre os grupos em relação à idade $(\mathrm{U}=7,50, p=0,293)$, à duração do relacionamento $(\mathrm{U}=8,00, p=0,282) \mathrm{e}$ à duração da vitimação $(\mathrm{U}=7,500, p=0,221)$. No que diz respeito ao nível educacional, encontrou-se uma diferença marginalmente significativa entre os grupos $(\mathrm{U}=4,000, p=0,065)$, apresentando o grupo de sucesso um nível educacional mais elevado.

No total foram codificadas 127 sessões em formato vídeo. Os grupos com sucesso e de insucesso terapêutico registaram uma média de 15 e de 11 sessões, respectivamente.

\section{Fidelidade}

Os dados foram codificados por dois juízes, respectivamente o juiz A (o segundo autor) e o juiz B (uma equipa composta pela terapeuta e outro juiz, estudante de doutoramento). O juiz A codificou todas as sessões da amostra (de forma "cega" relativamente ao resultado terapêutico, em termos de sucesso e insucesso), enquanto o juiz B codificou apenas as sessões em que os instrumentos de avaliação foram aplicados (sessões 1, 4, 8, 12, 16 e follow-up). Os juízes codificaram as sessões após ter sido recolhida toda a amostra de modo a evitar enviesamentos no processo terapêutico. $O$ cálculo da fidelidade do acordo inter-juízes foi realizado com os dados relativos a $30 \%$ da amostra (nomeadamente, $30 \%$ de cada caso), codificados pelos juízes A e B. A percentagem de acordo inter-juízes foi de $86 \%$ para a saliência $(85 \%$ e $87 \%$, relativos respectivamente aos grupos com sucesso e de insucesso). A fidelidade inter-juízes relativamente à tipologia de MIs foi calculada pelo Kappa de Cohen, obtendo-se o valor de 0,89. Devido ao elevado nível de fidelidade inter-juízes, a análise dos dados baseou-se na codificação efectuada pelo juiz A.

\section{Resultados}

O número de participantes em cada grupo $(N=5)$ da amostra aponta para a utilização de testes não paramétricos. No entanto, utilizou-se a estratégia de calcular ambos, testes paramétricos e os seus equivalentes não paramétricos, como aconselha Fife-Shaw (2006). Uma vez que as conclusões retiradas dos dois conjuntos de testes são as mesmas, optou-se por apresentar os resultados dos testes paramétricos. Estes são mais robustos e permitem utilizar análises multivariadas reduzindo, deste modo, o número de testes a efectuar e, logo, também a probabilidade do erro de Tipo I. 
Medidas do resultado terapêutico nos grupos com sucesso e insucesso

No que diz respeito ao Índice Geral de Sintomas (I.G.S. - medido pelo B.S.I., L. Derogatis, 1982; versão portuguesa adaptada de Canavarro, 1999) avaliado no início da intervenção, não houve diferenças quando se compararam os grupos com sucesso e de insucesso terapêutico $(t(8)=$ $-0,78, p=0,46)$.

No E.C.V.C. (Escala de Crenças acerca da Violência Conjugal, Machado, Matos \& Gonçalves, 2004) todas as clientes revelaram, nos três momentos de avaliação, uma tendência para discordar da maioria dos itens que compõem esta escala, demonstrando assim uma reduzida tolerância face à violência por parte do parceiro. As atitudes face à violência conjugal não foram significativamente diferentes em cada grupo $(\mathrm{U}=5,50, p=0,14)$.

Relativamente ao Inventário da Aliança Terapêutica (I.A.T., Horvath, 1982; versão portuguesa adaptada por Machado e Horvath, 1999) os resultados mostraram que os valores para a aliança terapêutica eram elevados para os dois grupos e para todas as sessões avaliadas (entre 182 e 252). Na quarta sessão, a qualidade da aliança terapêutica foi comparada nas três perspectivas avaliadas. Encontraram-se diferenças estatisticamente significativas entre os grupos com sucesso e de insucesso apenas de acordo com um observador $(\mathrm{U}=0,000 ; p=0,009)$, para o qual a aliança terapêutica era mais elevada no grupo de sucesso. Não se registaram diferenças significativas na perspectiva do outro observador $(\mathrm{U}=5,000 ; p=0,117)$ e na dos clientes $(\mathrm{U}=8,500 ; p=0,402)$.

\section{A emergência de MIs nos grupos com sucesso e insucesso}

Para testar diferenças estatisticamente significativas entre os grupos ao nível da saliência dos MIs (Figura 1), procedeu-se à análise univariada da covariância (ANCOVA) utilizando o número de sessões como covariante (dado o número diverso de sessões em que estiveram envolvidas as clientes). O grupo de sucesso (Estimated marginal mean $=153,05, S E=23,46$ ) evidenciou uma saliência dos MIs significativamente elevada, $F(1,7)=$ $7,08, p=0,032, \eta^{2}=0,50$, relativamente ao grupo de insucesso (Estimated marginal mean $=56,99, S E=23,46)$. 
Figura 1. Saliência dos tipos de MIs nos grupos de sucesso e de insucesso terapêutico.

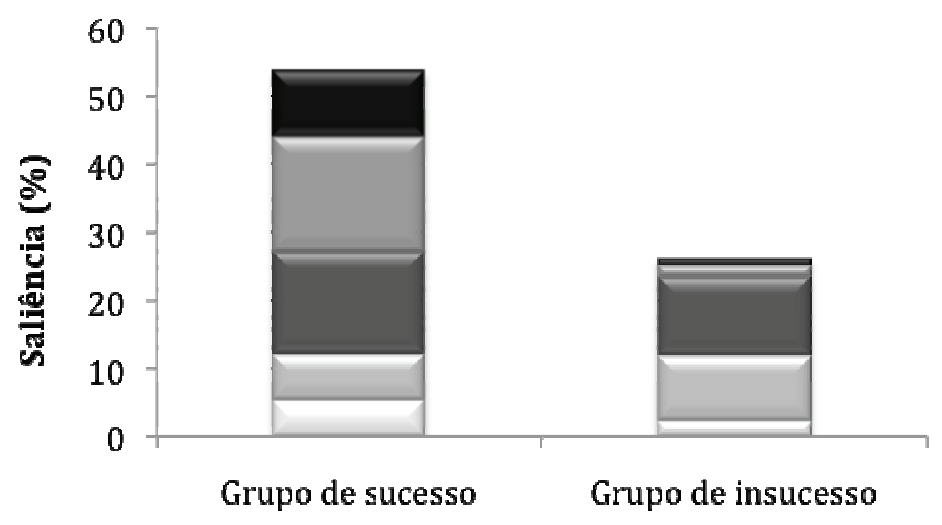

Grupos

$\triangle$ Acçăo $\square$ Reflexão $\square$ Protesto $\square$ Reconceptualizaçăo $\mathbf{D}$ Novas Experiências

Perfis dos momentos de inovação nos grupos com sucesso e insucesso

Uma análise multivariada da covariância (MANCOVA) foi calculada de modo a testar as diferenças entre os grupos no que respeita à saliência dos diferentes tipos dos MIs, utilizando o número de sessões como covariante (Quadro 2).

Não se verificaram diferenças significativas entre os dois grupos terapêuticos (Wilks' Lambda $=0,20, F(5,3)=2,47, p=0,24$ ), mas o grupo com sucesso terapêutico apresentou uma saliência significativamente mais elevada dos MIs de reconceptualização (Estimated marginal mean sucesso $=49,51 ;$ Estimated marginal mean insucesso $=3,75, S E=10,96$, $\left.F(1,7)=7,37, p=0,03, \eta^{2}=0,51\right)$ e novas experiências (Estimated marginal mean sucesso $=30,19 ;$ Estimated marginal mean insucesso $=-1,48, S E$ $\left.=8,15, F(1,7)=6,37, p=0,04, \eta^{2}=0,48\right)$, comparativamente com o grupo de insucesso.

Nos casos com insucesso, a saliência dos MIs de reconceptualização e de novas experiências era mais discreta e por vezes até ausente. Os níveis do I.G.S. diminuíram na sessão 4, momento em que estes dois tipos de MIs surgiram, mas voltaram a aumentar na sessão 8, onde os mesmos MIs estiveram ausentes. 
70 Miguel Gonçalves, Anita Santos, Marlene Matos, Inês Mendes e Carla Martins

Quadro 2. Saliência Global dos diferentes tipos de MIs ao longo da terapia.

\begin{tabular}{|c|c|c|c|c|}
\hline & $\begin{array}{c}\text { Grupo com Suces- } \\
\text { so Terapêutico } \\
(N=5)\end{array}$ & $\begin{array}{c}\text { Grupo com } \\
\text { Insucesso } \\
\text { Terapêutico } \\
\quad(N=5)\end{array}$ & & \\
\hline & $\operatorname{EMM}(S E)$ & EMM (SE) & $F(1,7)$ & $\eta^{2}$ \\
\hline Acção & $14,83(4,49)$ & $5,23(4,49)$ & 1,92 & 0,22 \\
\hline Reflexão & $19,20(4,68)$ & $19,12(4,68)$ & 0,001 & 0,00 \\
\hline Protesto & $39,33(6,75)$ & $30,38(6,75)$ & 0,74 & 0,10 \\
\hline Reconceptualização & $49,51(10,96)$ & $3,75(10,96)$ & $7,37^{*}$ & 0,51 \\
\hline Novas experiências & $30,19(8,15)$ & $-1,48(8,15)$ & $6,37 *$ & 0,48 \\
\hline
\end{tabular}

Figura 2. Saliência dos MIs de reconceptualização e novas experiências e valores do Índice Geral de Sintomas (I.G.S.) no grupo de sucesso terapêutico, relativamente às sessões de avaliação dos resultados terapêuticos.
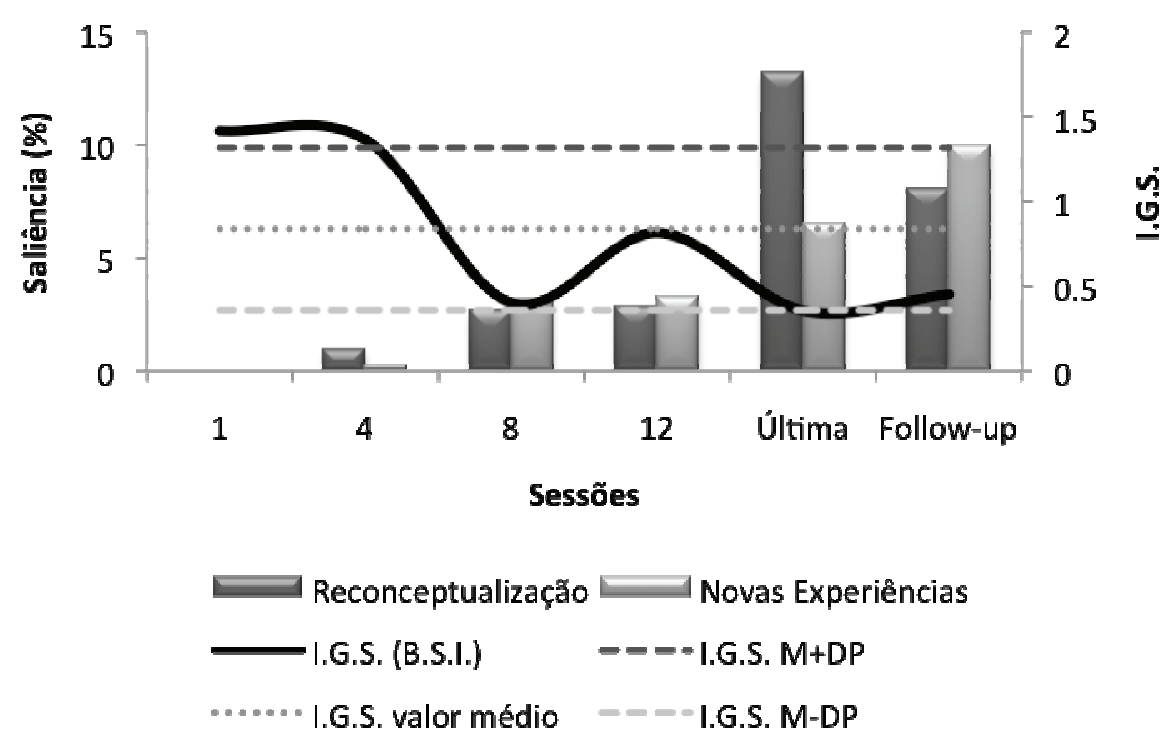
Figura 3. Saliência dos MIs de reconceptualização e novas experiências e valores do Índice Geral de Sintomas (I.G.S.) no grupo de insucesso terapêutico, relativamente às sessões de avaliação dos resultados terapêuticos.

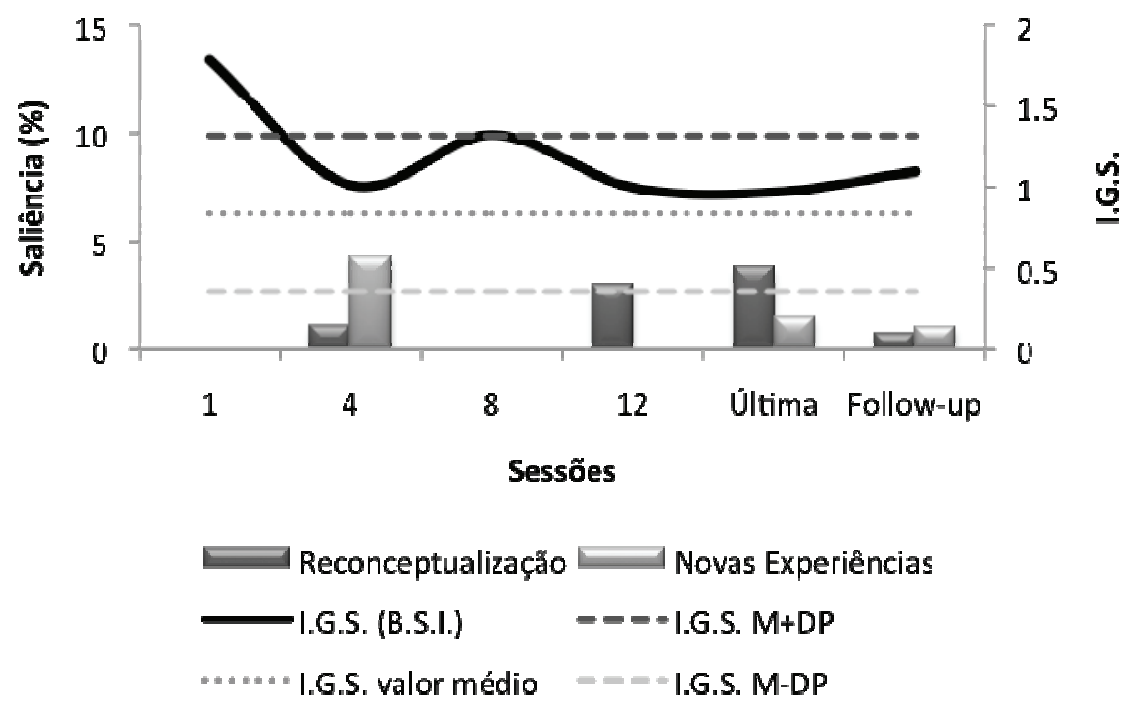

\section{Discussão}

Os resultados sugerem que os momentos de inovação são importantes na mudança psicoterapêutica.

Os grupos com sucesso e insucesso apresentam, globalmente, uma diferença significativa quanto à saliência de MIs, sendo esta mais elevada no grupo com sucesso. Esta dimensão parece estar relacionada com uma maior elaboração narrativa dos MIs neste grupo, suportando a ideia de que poderá ser um ingrediente importante, e não apenas a emergência de novidade por si só, como referem alguns terapeutas (ver, por exemplo, Freedman \& Combs, 1996, 2002, White \& Epston, 1990). Assim, o cliente pode relatar um MI, mas é devido às questões que o terapeuta coloca e aos detalhes que o cliente refere que um dado MI é elaborado narrativamente, aumentando a sua saliência.

Os MIs de reconceptualização e as novas experiências apresentam diferenças evidentes nos dois grupos. De facto, esses dois tipos praticamente não emergem nos casos com insucesso, sendo a sua saliência reduzida (ver Figura 3). Os resultados também sugerem que as diferenças na saliên- 
cia global dos MIs entre os grupos derivam essencialmente das diferenças verificadas ao nível dos MIs de reconceptualização e novas experiências.

Os resultados sugerem ainda uma evolução distinta dos MIs ao longo da terapia, atendendo às diferenças entre casos com sucesso e insucesso nas fases iniciais e finais do processo terapêutico. A evolução dos MIs de reconceptualização e novas experiências é claramente distinta: na maioria dos casos com sucesso, esses dois tipos emergem na fase intermédia da terapia e desenvolvem-se ao longo da fase final; por contraste, estão praticamente ausentes ao longo de todo o processo nos casos com insucesso.

Apresentamos de seguida uma proposta preliminar de interpretação dos dados, que estamos presentemente a procurar verificar se se replica noutros estudos e com diversas metodologias.

\section{A relevância da reconceptualização e das novas experiências}

Contrariamente ao que é proposto pelo modelo narrativo, a elaboração dos MIs não parece ser suficiente para a mudança ocorrer, tendo em conta os resultados acima descritos. Assim, dois tipos específicos de MIs são necessários para a mudança terapêutica ter lugar. Sugerimos anteriormente que os MIs de reconceptualização permitem que o cliente seja não só o actor da sua auto-narrativa, mas também e mais importante o seu autor (de acordo com a distinção proposta por Sarbin, 1986). Deste modo, a reconceptualização envolve um processo reflexivo acerca do próprio processo de mudança, uma vez que a pessoa consegue aceder ao mesmo. Como se pode constatar pela própria definição, estes MIs são os mais complexos, dado o envolvimento de uma meta-posição sobre a mudança, que permite uma descentralização do cliente e a capacidade de este observar o que se está a tornar diferente do "guião" anterior e os novos caminhos que pode percorrer na narrativa em construção. Estes MIs são proactivos e criativos, denotando uma preferência clara do cliente por esta nova história. Na nossa perspectiva, estes ingredientes são fundamentais para o desenvolvimento de uma posição de autoria sobre a mudança.

A emergência de outro tipo de MIs é também importante, enquanto marcadores de que algo novo está em desenvolvimento (e.g., novas acções, novos pensamentos, novas experiências), mas é a reconceptualização que permite a expansão de novidades mais ou menos elementares (i.e. episódicas) no sentido do desenvolvimento de novas e consolidadas auto-narrativas. Esta é uma hipótese que necessita de ser amplamente estudada em futuras investigações, mas pode explicar a ausência de diferenças entre os dois grupos nos MIs de acção, reflexão e protesto. Em ambos os grupos estes MIs parecem representar que algo novo está a ser desenvolvido, mas a reconceptualização apenas ocorre com saliência relevante no grupo com 
sucesso, facilitando a transformação e integração dos MIs anteriores numa nova narrativa. A reconceptualização parece assim actuar como um campo gravitacional que liga os outros MIs (acção, reflexão e protesto), conferindo-lhes uma estrutura e significado narrativo, devido à meta-posição que permite "olhar" para o processo de mudança e ligar a história "anterior" e a "nova". Sem estas dimensões, dificilmente qualquer MI se pode transformar numa nova história, dada a ausência de coerência e complexidade narrativa. Acções, reflexão ou protestos face uma vida dominada pelo problema podem ser facilmente esquecidos, levando a que a novidade se desvaneça.

Outros investigadores têm vindo a estudar aquilo que nós designamos por reconceptualização a partir de outras perspectivas. Por exemplo, Angus, Lewin, Bouffard e Rotondi-Trevisan, a propósito do processamento narrativo, sugerem que «a descentralização reflexiva e o posterior re-envolvimento com situações de vida difíceis ... facilita a articulação de novas compreensões acerca do self em relação aos outros" (2004, p. 90). A maior diferença entre o modo reflexivo e a reconceptualização é que no anterior todas as posições reflexivas do cliente são cotadas, enquanto no último apenas se codificam momentos de novidade (ou seja, MIs).

Tendo em conta o modelo de assimilação de Stiles (2006) e a sua perspectiva desenvolvimental acerca do processo terapêutico, os MIs de reconceptualização parecem relacionar-se com o estádio de insight/compreensão na sequência de assimilação das experiências problemáticas (APES-Assimilation of Problematic Experiences Sequence; Stiles, 2006). Esta fase em particular tem sido associada com resultados terapêuticos positivos e com a melhoria da sintomatologia (Detert, Llewelyn, Hardy, Barkham, \& Stiles, 2006; Stiles, 2006). A emergência dos MIs de reconceptualização e a sua elaboração ao longo do grupo com sucesso terapêutico parece coincidir com uma diminuição da sintomatologia, medido pelo I.G.S. Assim, sugere-se que a evolução dos MIs de acção, reflexão e protesto reflectem os estádios de assimilação que precedem o movimento de transição para o insight/compreensão da experiência problemática (Brinegar, Salvi, Stiles, \& Greenberg, 2006; Detert et al., 2006). Esta fase do processo terapêutico implica que a voz problemática é assimilada na comunidade de vozes dominante pela construção de "pontes de significado". Estas definem-se pela forma como ligam as vozes através da mútua compreensão, envolvendo-se em acções conjuntas e constituindo-se como futuros recursos para o cliente (Brinegar et al., 2006). Deste modo, a emergência dos MIs de reconceptualização parece favorecer o desenvolvimento de uma "ponte de significado" entre as posições anteriores (e.g. vítima) e (re)emergentes (e.g. profissional, companheira) das clientes, promovendo a compreensão do problema e do processo envolvido na sua superação. 
De uma perspectiva diferente, Hermans (2003) sugere que um processo dialógico importante ocorre na terapia bem sucedida: a emergência de uma metaposição, uma posição a partir da qual as outras auto-posições podem ser observadas e avaliadas (ver também Dimaggio, Salvatore, Azzara \& Catania, 2003; Leiman \& Stiles, 2001). De facto, para codificar um MI de reconceptualização, tal como se referiu anteriormente, duas posições precisam de estar presentes: o self anterior e o self emergente, o que significa que uma meta-posição é necessária.

A coerência e a estrutura que o MI de reconceptualização permite estão certamente relacionadas com a emergência de novas experiências. Note-se que as novas experiências estão quase ausentes nos casos de insucesso. Os MIs de novas experiências representam a expansão das narrativas emergentes para o futuro. A pessoa necessita de ser capaz de se imaginar em posições futuras para que o movimento para o futuro ocorra (ver por exemplo Markus \& Nurius, 1986). Como Valsiner (2004) propõe «a pessoa está constantemente a criar significado antecipado em relação à altura em que este pode ser necessário» (p. 14).

Do nosso ponto de vista, para que a história seja expandida para o futuro, uma meta-posição como a que a reconceptualização permite é necessária. A partir dela é possível imaginar um futuro com outras possibilidades fora da narrativa problemática.

Em suma, sugerimos que a mudança ocorre através de um processo cíclico, que pode ter início com MIs de acção, reflexão e protesto, como sinais para o próprio e para os outros de que algo diferente está a acontecer. Os MIs de reconceptualização ocupam a fase seguinte do ciclo, permitindo a criação de uma meta-posição, que permite que a pessoa se distancie e se veja a si própria a mudar, assim como as diferenças entre auto-narrativa "anterior" e "emergente". Diversos movimentos desde acção, reflexão e protesto através da reconceptualização, e de novo de volta à acção, reflexão e protesto (isto é, sinais de que a mudança está realmente a acontecer), podem ser necessários para validar a mudança, antes de a pessoa ser capaz de se projectar no futuro com uma nova narrativa. Cada ciclo pode ser amplificado pela validação de outros significativos, o que pode promover novos ciclos de exploração de novidade (ver Figura 4).

Evidentemente, outras linhas de desenvolvimento são plausíveis, sendo particularmente necessário investigar diferentes possibilidades de mudança. Por exemplo, entendemos que é possível um processo de mudança ser iniciado pelo protesto, desenvolvendo posteriormente MIs de acção e reflexão e, a partir daí, reconceptualização e novas experiências. Ou, pode também começar por se vislumbrar uma nova narrativa (MI de reconceptualização) e daí desenvolver os mais concretos MIs de acção e reflexão, embora até ao momento não tenhamos nas nossas investigações casos em que isto aconteça. 
Figura 4. MIs e a criação de uma nova narrativa.

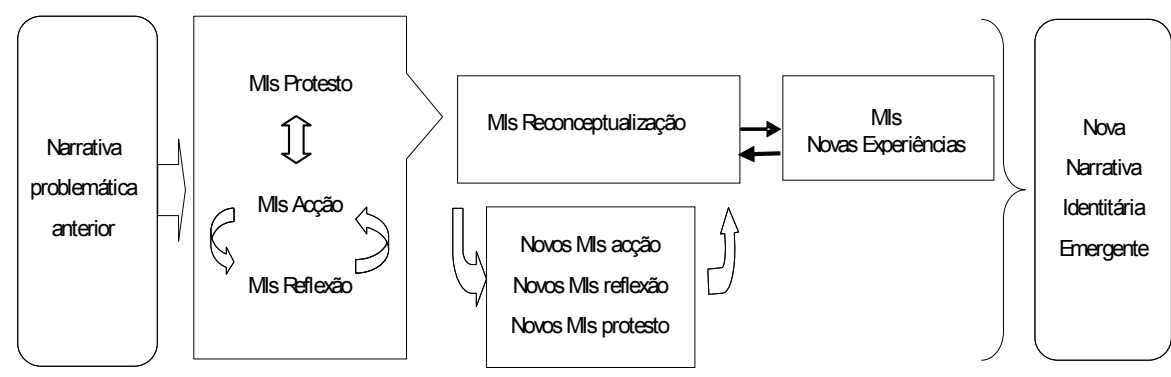

Evoluçăo da terapia

Independentemente do "ponto de partida", a nossa proposta é que uma gestalt de MIs é necessária para o desenvolvimento de uma história significativa, a qual se desenvolve através de num processo cíclico, semelhante ao descrito na Figura 4, apesar de esse caminho não ser, provavelmente, o único possível.

\section{Limitações}

No que se refere à amostra, uma das limitações deste estudo prende-se com a diferença marginalmente significativa entre os grupos contrastantes relativamente ao nível educacional e ainda as cotações da aliança terapêutica por um dos observadores. Assim, as diferenças entre os grupos podem ser parcialmente explicadas por estas discrepâncias em detrimento das diferenças encontradas nos MIs. Por outro lado, dado o tamanho reduzido da amostra e o foco nas vítimas de violência na intimidade, as conclusões são necessariamente limitadas e a possibilidade de generalização a outros processos de mudança é restrita.

Também é importante referir que, apesar da conclusão de que os MIs promovem a mudança terapêutica, outras condições podem ter interferido com o desenvolvimento da terapia (e.g., hesitação perante a mudança, falta de validação social dos MIs, papel das audiências). Além disso, embora tenha sido realizada uma sessão de follow-up, teria sido importante avaliar os casos novamente (e.g., um ano após o término da terapia) para corroborar os resultados terapêuticos.

O facto de os processos terem sido acompanhados sempre pela mesma terapeuta é outra importante limitação, embora tenham sido tomadas todas as precauções para evitar enviesamentos no processo de codificação (e.g., codificação "cega", codificação após o término das sessões). 


\section{Implicações}

Este estudo exploratório é pioneiro na análise da mudança terapêutica através de uma nova metodologia - Sistema de Codificação dos Momentos de Inovação (Gonçalves, Matos \& Santos, 2006). Este método permite-nos identificar, de forma consistente, detalhes narrativos que são excepção à narrativa dominante e apontar as diferenças entre grupos com sucesso e com insucesso terapêutico.

Neste momento, estamos a desenvolver outros estudos empíricos, que replicam esta metodologia com modelos terapêuticos diversos (e.g., cognitivo, experiencial) e diferentes populações (e.g., pacientes com depressão). Assim, é nosso intuito comparar diferentes estudos ao nível do processo terapêutico, para testar se os padrões já encontrados se replicam e, eventualmente, identificar outros padrões de construção da mudança em psicoterapia.

\section{Referências}

Angus, L. E., \& McLeod, J. (Eds.) (2004). The handbook of narrative psychotherapy: Practice, theory and research. London: Sage.

Angus, L. E., Lewin, J., Bouffard, B., \& Rotondi-Trevisan, D. (2004). "What's the story?" Working with narratives in experiential psychotherapy. In L. E. Angus \& J. Mcleod (Eds.), The handbook of narrative psychotherapy: Practice, theory and research (pp. 87-102). London: Sage.

Brinegar, M. G., Salvi, L. M., Stiles, W. B., \& Greenberg, L. S. (2006). Building a meaning bridge: Therapeutic progress from problem formulation to understanding. Journal of Counseling Psychology, 53, 165-180.

Bruner, J. (1986). Actual minds, possible worlds. Cambridge, MA: Harvard University Press.

Canavarro, M. C. S. (1999). Inventário de sintomas psicopatológicos - B. S. I. In M. R. Simões, M. M. Gonçalves \& L. S. Almeida (Eds.), Testes e provas psicológicas em Portugal [Tests and psychological instruments in Portugal], Vol. II (pp. 95-109). Braga: APPORT/SHO.

Derogatis, L. R. (1982). Self-report measures of stress. In L. Goldberger \& S. Brenznitz (Eds.), Handbook of stress: Theoretical and clinical aspects (pp. 270-290). New York: Free Press.

de Shazer, S. (1991). Putting difference at work. New York: Norton.

deShazer, S. (1994). When words were originally magic. New York: W.W. Norton.

Detert, N. B., Llewelyn, S. P., Hardy, G. E., Barkham, M., \& Stiles, W. B. (2006). Assimilation in good- and poor-outcome cases of very brief psychotherapy for mild depression: An initial comparison. Psychotherapy Research, 16, 393-407. 
Dimaggio, G., Salvatore, G., Azzara, C., \& Catania, D. (2003). Rewriting self-narratives: The therapeutic process. Journal of Constructivist Psychology, 16, 155-181.

Fife-Schaw, C. (2006). Levels of Measurement. In G. M. Breakwell, S. Hammond, C. Fife-Schaw, \& J. A. Smith (Eds.), Research Methods in Psychology ( $3^{\text {rd }}$ Edition). London: Sage.

Freedman, J., \& Combs, G. (1996). Narrative therapy: The social construction of preferred realities. New York: Norton.

Freedman, J. \& Combs, G. (2002). Narrative couple therapy. In A. S. Gurman \& N. S. Jacobson (Eds.), Clinical handbook of couple therapy (pp. 308-334)(3 ${ }^{\text {rd }}$ Ed.). New York: Guilford Press.

Gonçalves, M. M., Matos, M., \& Santos, A. (2006). Sistema de codificação dos Momentos de Inovação: Versão 1. Braga. Universidade do Minho, disponível a pedido aos autores.

Gonçalves, M., M., Matos, M., \& Santos, A. (2009). Narrative therapy and the nature of "innovative moments" in the constrution of change. Jounal of Constructivist Psichology, 22, 1-23.

Gonçalves, M. M. (2008). Terapia centrada nas soluções. Braga: Colecção Cadernos de Psicoterapia, Psiquilibrios Edições.

Hermans, H. J. M. (2003). The construction and reconstruction of a dialogical self. Journal of Constructivist Psychology, 16, 89-130.

Horvath, A. (1982). Users' manual of the Working Alliance Inventory. Manuscrito não publicado. Simon Frase University. Canadá.

Hoyt, M. F. (Ed.) (1998). Handbook of constructive therapies. New York: Guilford.

Leiman, M., \& Stiles, W. B. (2001). Dialogical sequence analysis and the zone of proximal development as conceptual enhancements to the assimilation model: The case of Jan revisited. Psychotherapy Research, 11, 311-330.

Machado, C., Matos, M., \& Gonçalves, M. M. (2004). Escala de crenças sobre a violência conjugal (ECVC). In L. S. Almeida, M. R. Simões, C. Machado \& M. M. Gonçalves (Coords.), Avaliação psicológica: Instrumentos validados para a população portuguesa - Volume II [Psychological assessment: Validated instruments for the Portuguese population - vol. II] (pp. 127-140). Coimbra: Quarteto.

Machado, P. P., \& Horvath, A. (1999). Inventário da aliança terapêutica - W. A. I.. In M. R. Simões, M. M. Gonçalves \& L. S. Almeida (Eds.), Testes e provas psicológicas em Portugal, Vol. II [Tests and psychological instruments in Portugal, volume II] (pp. 87-94). Braga: APPORT/SHO.

Madigan, M., \& Law, I. (1998) (eds.), Praxis: Situating discourse, feminism and politics in narrative therapies. Vancouver: Cardigan Press.

Markus, H., \& Nurius, P. (1986). Possible selves. American Psychologist, 41, 954$-969$.

Martin, A., Berenson, K., Griffing, S., Sage, R., Madry, L., Bingham, L., \& Primm, B. (2000). The process of leaving an abusive relationship: The role of risk assessments and decision-certainty. Journal of Family Violence, 2, 109-122. 
Matos, M. (2006). Violência nas relações de intimidade: Estudo sobre a mudança terepêutica na mulher. Tese de doutoramento não publicada. Braga: Instituto de Educação e Psicologia, Universidade do Minho.

Matos, M., \& Gonçalves, M. M. (2004). Narratives on marital violence: The construction of change through re-authoring. In R. Abrunhosa, R. Roesch, C. Machado, C. Soeiro \& F. Winkel (Eds.), Assessment, intervention and legal issues with offenders and victims (pp. 137-154). Bruxelas: Politea.

Matos, M., Machado, C., \& Gonçalves, M. (2000). E.C.V.C. - Escala de crenças sobre a violência conjugal [Scale of beliefs of marital violence]. Braga: Universidade do Minho, I.E.P.

Monk, G., Winslade, J., Crocket, K., \& Epston, D. (1997). Narrative therapy in practice: The archaeology of hope (pp. 161-170). San Francisco: Jossey-Bass.

Neimeyer, R. A., \& Raskin, J. D. (Eds.) (2000). Constructions of disorder: Meaning-making frameworks for psychotherapy (pp. 207-242). Washington: American Psychological Association.

O’Hanlon, B. (1998). Possibility therapy: An inclusive, collaborative, solution-based model of therapy. In M. F. Hoyt (Ed.), The handbook of constructive therapies: Innovative approaches from leading practitioners (pp. 137-158). San Francisco: Jossey-Bass.

Omer, H., \& Alon, N. (1997). Constructing therapeutic narratives. Northvale, N. J.: Jason Aronson.

Parry, A., \& Doan, R. D. (1994). Story re-visions. New York: Guilford Press.

Sarbin, T. R. (Ed.) (1986). The narrative and the root metaphor for psychology. In T. R. Sarbin (Ed.), Narrative psychology: The storied nature of human conduct (pp. 3-21). New York: Praeger.

Smith, C., \& Nylund, D. (1997). Narrative therapies with children and adolescents. New York: Guilford.

Stiles, W. B. (2006). Assimilation and the process of outcome: Introduction to a special section. Psychotherapy Research, 16, 389-392.

Valsiner, J. (2004). The promoter sign: Developmental transformation within the structure of Dialogical Self. Paper presented at the Symposium (Hubert Hermans, Convener) Developmental aspects of the dialogical self. ISSBD, Gent, July 12, 2004.

White, M. (1994). Deconstruction and therapy. In D. Epston \& M. White (Eds.), Experience, contradiction, narrative and imagination (pp. 109-152) $\left(2^{\text {nd }}\right.$ Ed.). Adelaide: Dulwich Centre Publications.

White, M. (2004). Narrative practices and exotic lives: Resurrecting diversity in everyday life. Adelaide: Dulwich Centre Publications.

White, M. (2007). Maps of narrative practice. New York: Norton.

White, M., \& Epston, D. (1990). Narrative means to therapeutic ends. New York: Norton.

Winslade, J., \& Monk, G. (1999). Narrative counselling in schools. California: Corvin Press.

Zimmerman, J. L., \& Dickerson, V. C. (1996). If problems talked: Narrative therapy in action. New York: Guilford. 